\title{
Supporting Information: Identifying and Tuning the In Situ Oxygen-Rich Surface of Molybdenum Nitride Electrocatalysts for Oxygen Reduction
}

Michaela Burke Stevens ${ }^{1,2} \dagger$, Melissa E. Kreider ${ }^{1,2} \dagger$, Anjli M. Patel ${ }^{1,2}$, Zhenbin Wang ${ }^{3}$, Yunzhi Liu $^{4}$, Brenna M. Gibbons ${ }^{2,4}$, Michael J. Statt ${ }^{1,2}$, Anton V. Ievlev ${ }^{5}$, Robert Sinclair ${ }^{4}$, Apurva Mehta $^{6,7}$, Ryan C. Davis ${ }^{6,7}$, Jens K. Nørskov ${ }^{3 *}$, Alessandro Gallo ${ }^{2,6}$, Laurie A. King ${ }^{8 *}$, Thomas F. Jaramillo $^{1,2^{*}}$

$\dagger$ These authors contributed equally

* Corresponding authors (jaramillo@stanford.edu, L.King@mmu.ac.uk, and jkno@dtu.dk)

1) Department of Chemical Engineering, Stanford University 443 Via Ortega, Stanford, CA 94305, USA

2) SUNCAT Center for Interface Science and Catalysis, SLAC National Accelerator Laboratory, Menlo Park, CA 94025, USA

3) Department of Physics, Technical University of Denmark, 2800 Kongens Lyngby, Denmark

4) Department of Materials Science and Engineering, Stanford University, 496 Lomita Mall, Stanford, CA 94305 USA

5) Center for Nanophase Materials Sciences, Oakridge National Laboratory, Oak Ridge, TN 37831, USA

6) SLAC National Accelerator Laboratory, 2575 Sand Hill Road, Menlo Park, CA, 94025 USA

7) Stanford Synchrotron Radiation Lightsource, SLAC National Accelerator Laboratory, Menlo Park, CA 94025, USA

8) Faculty of Science and Engineering, Manchester Metropolitan University, Chester Street, Manchester, M1 5GD, UK 
Table S1. Summary of XPS peak fitting results for the MoN films after $\sim 1$ week in air, 11 months in air, $5 \mathrm{~s}$ at $\mathrm{OCV}$, and $1 \mathrm{~h} \mathrm{CA}$ at $0.3 \mathrm{~V}$ vs RHE.

\begin{tabular}{|c|c|c|c|c|}
\hline Treatment & $\sim 1$ week in air & 11 months in air & $5 s$ at $O C V$ & 1h CA (0.3 V vs RHE) \\
\hline Peak & Mo-N (3d, 3p) & Mo-N (3d, 3p) & Mo-N (3d, 3p) & Mo-N (3d, 3p) \\
\hline $\begin{array}{c}\text { Peak Position } \\
\text { (eV) }\end{array}$ & $\begin{array}{l}229.6 / 232.7 \\
395.8 / 412.8\end{array}$ & $\begin{array}{l}229.6 / 232.7 \\
395.4 / 412.4\end{array}$ & $\begin{array}{l}229.9 / 233.0 \\
395.9 / 412.9\end{array}$ & $\begin{array}{l}229.8 / 232.9 \\
396.0 / 413.0\end{array}$ \\
\hline Peak \% & 42 & 9 & 57 & 58 \\
\hline Peak & $\mathrm{Mo}-\mathrm{O}_{2}(3 \mathrm{~d}, 3 p)$ & $\mathrm{Mo}-\mathrm{O}_{2}(3 \mathrm{~d}, 3 p)$ & $\mathrm{Mo}-\mathrm{O}_{2}(3 \mathrm{~d}, 3 p)$ & $\mathrm{Mo}-\mathrm{O}_{2}(3 \mathrm{~d}, 3 \mathrm{p})$ \\
\hline $\begin{array}{c}\text { Peak Position } \\
\text { (eV) }\end{array}$ & $\begin{array}{l}231.1 / 234.3 \\
398.0 / 415.0\end{array}$ & $\begin{array}{l}231.3 / 234.4 \\
397.0 / 414.0\end{array}$ & $\begin{array}{l}231.3 / 234.4 \\
398.0 / 415.0\end{array}$ & $\begin{array}{l}231.2 / 234.4 \\
398.2 / 415.2\end{array}$ \\
\hline Peak \% & 10 & 5 & 15 & 15 \\
\hline Peak & $\mathrm{Mo}-\mathrm{O}_{3}(3 \mathrm{~d}, 3 p)$ & $\mathrm{Mo}^{-\mathrm{O}_{3}}(3 \mathrm{~d}, 3 \mathrm{p})$ & $\mathrm{Mo}^{-\mathrm{O}_{3}}(3 \mathrm{~d}, 3 p)$ & $\mathrm{Mo}-\mathrm{O}_{3}(3 \mathrm{~d}, 3 \mathrm{p})$ \\
\hline $\begin{array}{c}\text { Peak Position } \\
(\mathrm{eV})\end{array}$ & $\begin{array}{l}233.0 / 236.1 \\
399.1 / 416.1\end{array}$ & $\begin{array}{l}233.0 / 236.1 \\
398.9 / 416.0\end{array}$ & $\begin{array}{l}232.8 / 236.0 \\
399.1 / 416.1\end{array}$ & $\begin{array}{l}232.8 / 236.0 \\
399.2 / 416.2\end{array}$ \\
\hline Peak \% & 48 & 86 & 28 & 27 \\
\hline Peak & N-Mo (N 1s) & N-Mo (N 1s) & N-Mo (N 1s) & N-Mo (N 1s) \\
\hline $\begin{array}{c}\text { Peak Position } \\
\text { (eV) }\end{array}$ & 397.5 & 397 & 397.8 & 397.8 \\
\hline Peak \% & 48 & 20 & 100 & 100 \\
\hline Peak & $\mathrm{N}-\mathrm{O}$ & $\mathrm{N}-\mathrm{O}$ & - & - \\
\hline $\begin{array}{c}\text { Peak Position } \\
(\mathrm{eV})\end{array}$ & 402.1 & 402 & - & - \\
\hline Peak \% & 52 & 80 & - & - \\
\hline
\end{tabular}
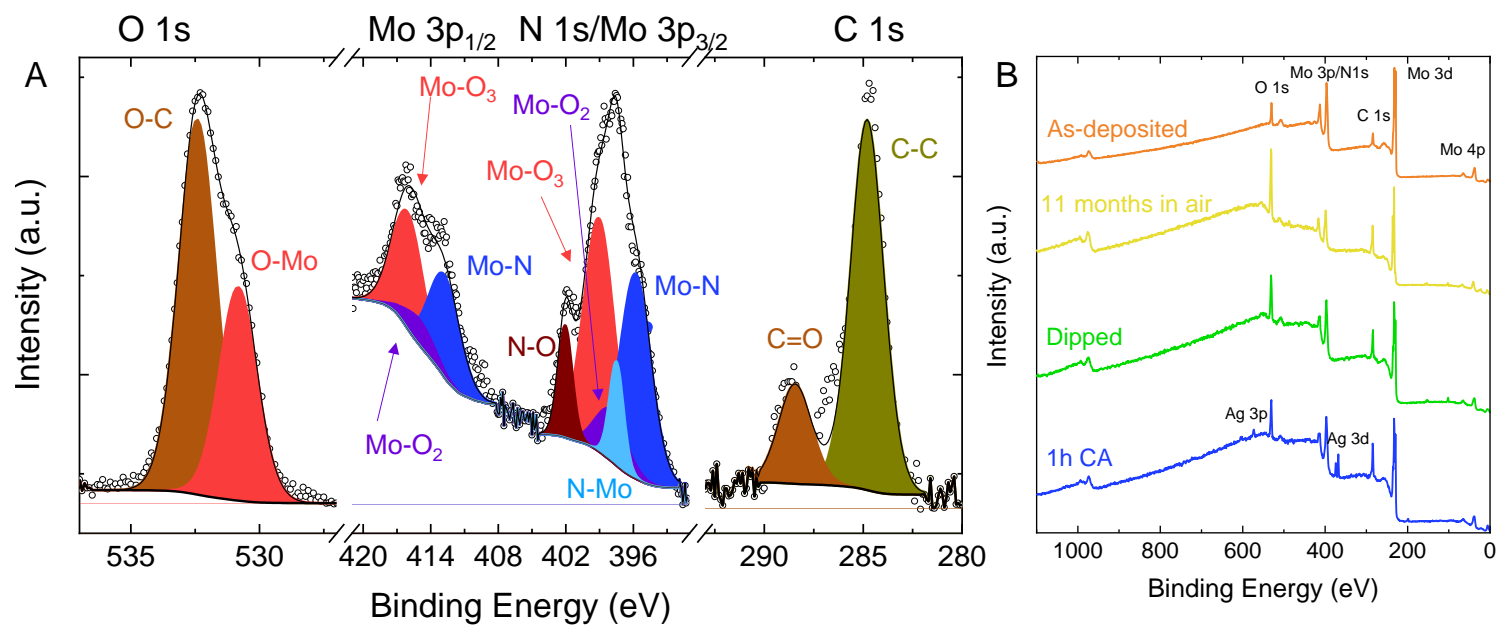

Figure S1. (A) XPS peak deconvolution for the as-deposited MoN film shown in Figure 1A. The $\mathrm{N}$ 1s peak is deconvoluted by fitting the full Mo 3p spectrum, using the peak ratios for each Mo oxidation state from Mo 3d. The area ratio and peak splitting between the Mo $3 \mathrm{p}_{3 / 2}$ and Mo $3 \mathrm{p}_{1 / 2}$ peaks are 2:1 and $17 \mathrm{eV}$, respectively. The $\mathrm{N}$ peak fills the remainder of area, at approximately $397 \mathrm{eV}$, in the Mo 3p $3 / 2$ region. (B) Survey scans for the $4 \mathrm{MoN}$ films shown in Figure 1A. The small amount of Ag contamination observed after the 1h CA experiment is due to a leaking $\mathrm{Ag} / \mathrm{AgCl}$ reference electrode. 

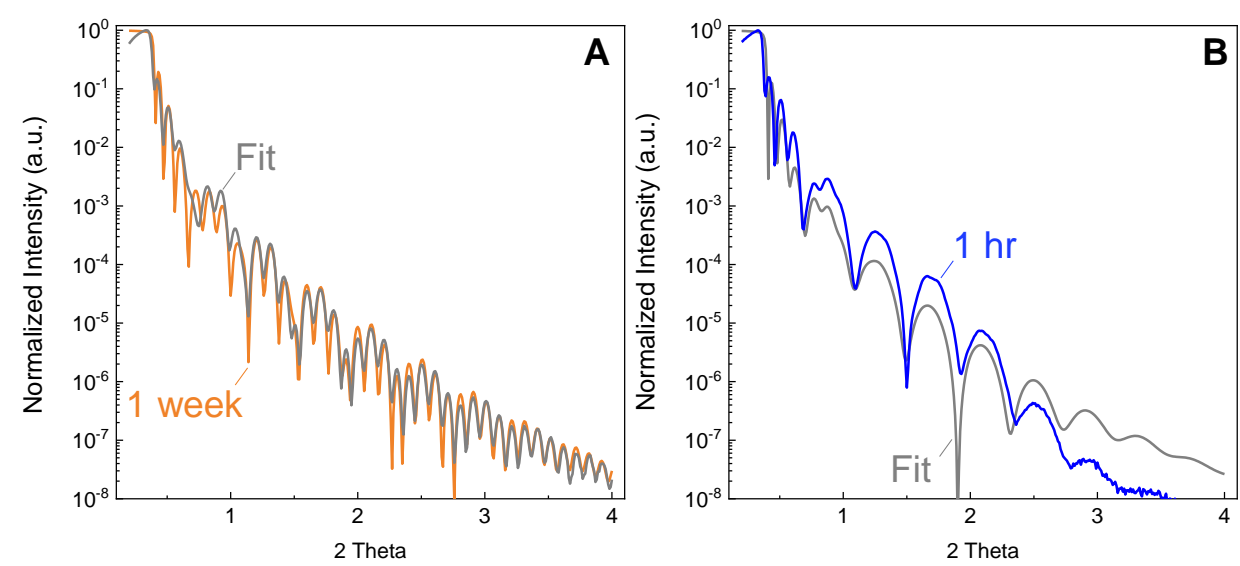

\begin{tabular}{|c|c|c|c|}
\hline \multicolumn{4}{|c|}{ XRR Fits 1 Week (FOM: 1.72 e-01) } \\
\hline Layer & $\begin{array}{c}\text { Density } \\
\left(\mathbf{g ~ c m}^{-2}\right)\end{array}$ & $\begin{array}{c}\text { Thickness } \\
\text { (nm) }\end{array}$ & $\begin{array}{c}\text { Roughness } \\
\text { (nm) }\end{array}$ \\
\hline $\mathrm{MoO}_{3}$ & 2.8 & 2.3 & 0.4 \\
\hline $\mathrm{MoN}$ & 7.8 & 29.0 & 1.7 \\
\hline $\mathrm{Ti}$ & 4.0 & 10.0 & 0.6 \\
\hline $\begin{array}{c}\mathrm{Si} \\
\text { (Substrate) }\end{array}$ & 2.33 & $\mathrm{na}$ & 0.2 \\
\hline
\end{tabular}

\begin{tabular}{|c|c|c|c|}
\hline \multicolumn{4}{|c|}{ XRR Fits 1 Week (FOM: 4.45 e-01) } \\
\hline Layer & $\begin{array}{c}\text { Density* } \\
\left(\mathbf{g ~ c m}^{\mathbf{2}}\right)\end{array}$ & $\begin{array}{c}\text { Thickness } \\
\text { (nm) }\end{array}$ & $\begin{array}{c}\text { Roughness } \\
\text { (nm) }\end{array}$ \\
\hline $\mathrm{MoO}_{3}$ & 5.5 & 2.2 & 3.5 \\
\hline $\mathrm{MoN}$ & 7.8 & 28.5 & 1.7 \\
\hline $\mathrm{Ti}$ & 3.96 & 10.0 & 0.6 \\
\hline $\begin{array}{c}\mathrm{Si} \\
\text { (Substrate) }\end{array}$ & 2.33 & na & 0.2 \\
\hline
\end{tabular}

Figure S2. XRR and approximate models for MoN sample after A) 1 week in air and B) 1h CA at $0.3 \mathrm{~V}$ vs RHE in $0.1 \mathrm{M} \mathrm{HClO}_{4}$. Fits correspond to data in main paper Figure 1C. Note: Density is calculated using an assumed formula from a fit atomic density (atoms $\mathrm{cm}^{-3}$ ). The mass density in grams would be different if the composition were different. For simplicity we kept the surface composition the same, however, it is likely that compositional changes are responsible for the changes in mass density.

Table S2. EXAFS fitting results

\begin{tabular}{|c|c|c|c|c|c|c|}
\hline \multicolumn{7}{|c|}{ Surface } \\
\hline Sample & R-factor & $\mathrm{X}^{2}$ & $\begin{array}{c}\text { Free } \\
\text { Parameters }\end{array}$ & R-factor & $X^{2}$ & $\begin{array}{c}\text { Free } \\
\text { Parameters }\end{array}$ \\
\hline 1 week in air & 0.03 & 471 & 3.06 & 0.013 & 821 & 5.06 \\
\hline $1 \mathrm{~h} \mathrm{CA}$ & 0.007 & 333 & 3.06 & 0.041 & 1531 & 5.06 \\
\hline 5 s at OCV & 0.017 & 727 & 3.06 & 0.012 & 3268 & 5.06 \\
\hline $0.5 \mathrm{~V}$ & 0.023 & 5924 & 5.06 & 0.026 & 5924 & 5.06 \\
\hline $0.3 \mathrm{~V}(\mathrm{a})$ & 0.054 & 1141 & 5.06 & 0.032 & 6408 & 5.06 \\
\hline $0.7 \mathrm{~V}$ & 0.013 & 1671 & 5.06 & 0.006 & 1512 & 5.06 \\
\hline $0.3 \mathrm{~V}(\mathrm{~b})$ & 0.028 & 2815 & 5.06 & 0.01 & 3470 & 5.06 \\
\hline $0.8 \mathrm{~V}$ & 0.0106 & 798 & 5.06 & 0.03 & 5905 & 5.06 \\
\hline $0.3 \mathrm{~V}(\mathrm{c})$ & 0.024 & 2027 & 5.06 & 0.03 & 6970 & 5.06 \\
\hline $0.9 \mathrm{~V}$ & 0.049 & 1787 & 3.06 & 0.03 & 2076 & 1.06 \\
\hline
\end{tabular}

Notes on R-factor and $\chi^{2}$ : The R-factor and $\chi^{2}$ are statistical measures of the goodness of the fit, which incorporate the difference between the fit and the data at every point, the number of independent points, the number of points to be fit, and the estimated noise level in the data. ${ }^{1}$ 


$$
\begin{gathered}
R-\text { factor }=\frac{\sum_{i=1}^{N}\left(\text { data }_{i}-f_{i t}\right)^{2}}{\sum_{i=1}^{N} \text { data }_{i}^{2}} \\
\mathrm{X}^{2}=\frac{N_{\text {ind }}}{\epsilon N_{\text {data }}} \sum_{i=1}^{N}\left(\text { data }_{i}-f_{i}\right)^{2} \\
\epsilon=\text { estimated noise level in the data } \\
N_{\text {ind }}=\text { \# of independent points } \\
N_{\text {data }}=\text { \# of points in the data to fit }
\end{gathered}
$$

Figure S3. R-factor values for the surface EXAFS fits. Blue circles denote spectra fit with Mo-N and Mo-Mo paths only. Red stars denote spectra fit with Mo-O, Mo-N, and Mo-Mo paths. For the conditions shown with both blue and red fits, the red were chosen as better fits. The quality of the fits were evaluated on the bases of R-factor, reduced chi-square, and physical reasonableness.

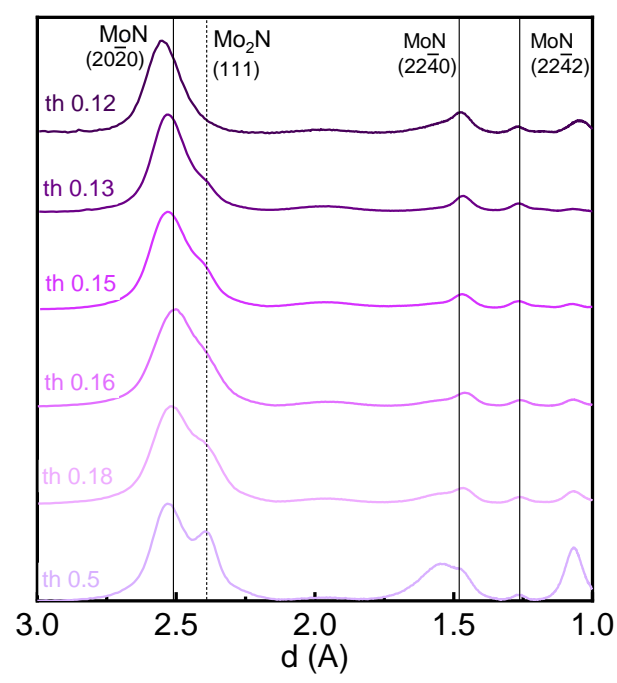

Figure S4. GI-XRD of the MoN film at incident angles of $0.12-0.5$ showing the surface hexagonal MoN structure and mix of hexagonal $\mathrm{MoN}$ and cubic $\mathrm{Mo}_{2} \mathrm{~N}$ structures in the bulk. As previously described, a refraction correction was used to account for differences in refraction of 
x-rays traveling different lengths in the film, allowing for the comparison of diffractograms at the various incidence angles. Figure has been reproduced with permission from ref (2) Copyright 2020 American Chemical Society
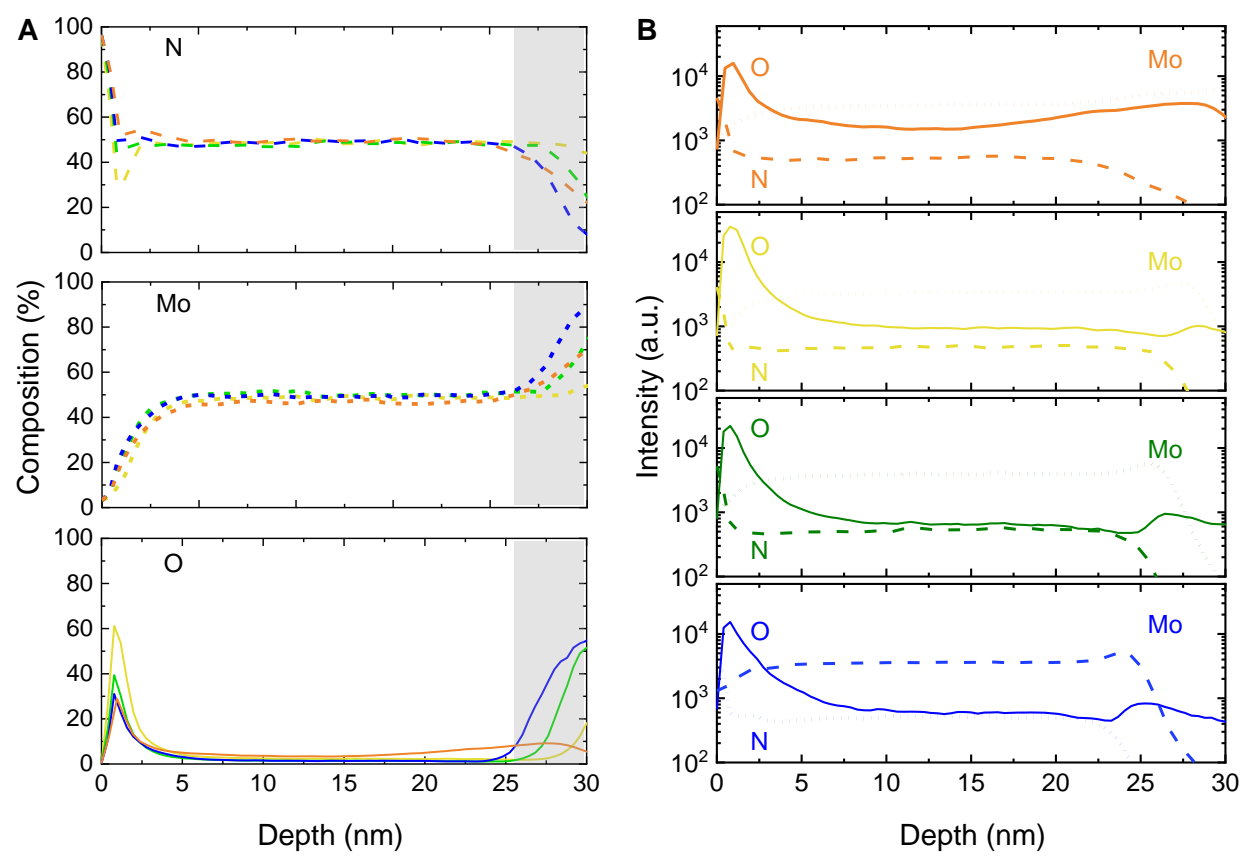

Figure S5. ToF-SIMS depth profiles. (A) Percent composition and (B) raw intensity of N (dash), Mo (dot), and $\mathrm{O}$ (line) throughout the depth of the $\sim 1$ week in air (orange), 11 months in air (yellow), 5s at OCV (green), and 1h CA (blue) films. Conversion from raw ToF-SIMS intensities to composition was done using XPS spectra, as described previously. The grey boxes highlight the approximate area where the film ends and Ti sticking layer signal starts. Data for the 1 week in air samples have been reproduced with permission from ref (2) Copyright 2020 American Chemical Society.
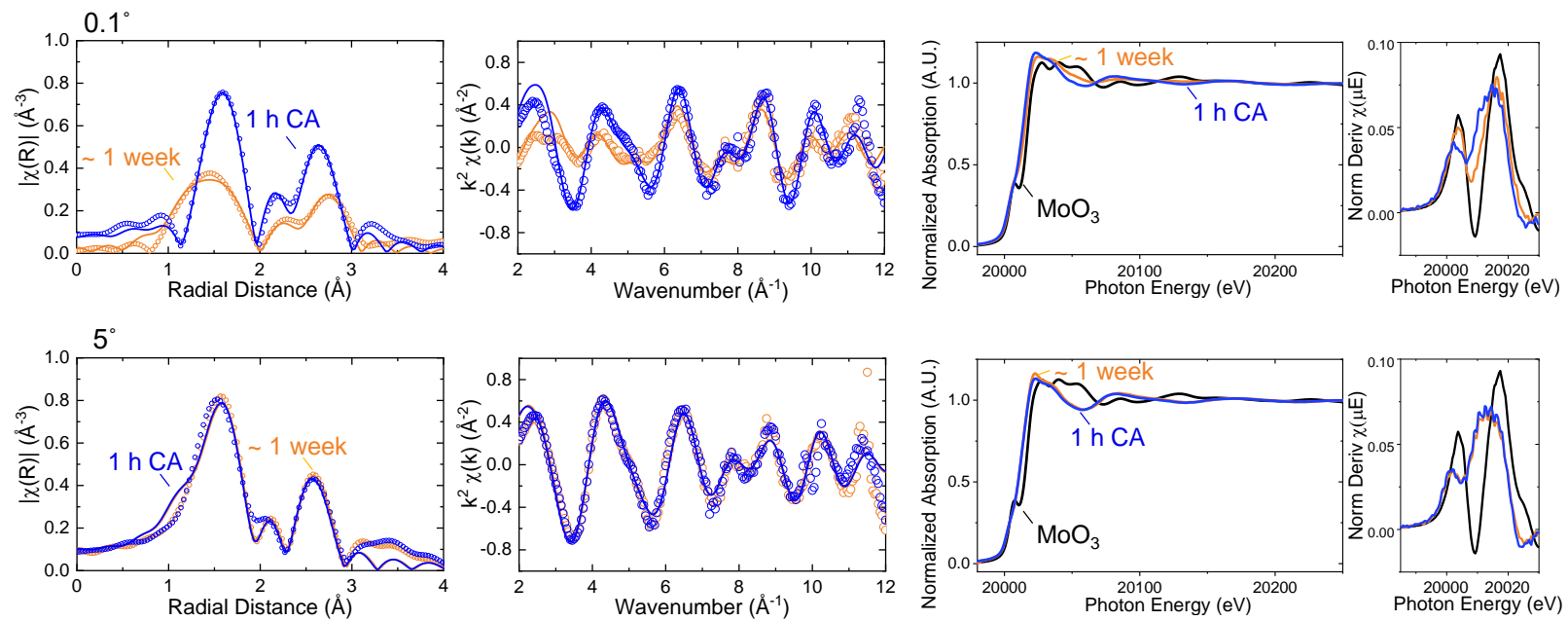
Figure S6. Surface (top) and bulk (bottom) ex situ XANES \& EXAFS of the MoN sample after 1 week (orange) in air and $1 \mathrm{hrCA}$ at $0.3 \mathrm{~V}$ vs $\mathrm{RHE}$ in $0.1 \mathrm{M} \mathrm{HClO}_{4}$ (blue). Data (circles) and fits (lines) correspond to main paper Figure 1D and F. Data for the bulk 1 week in air sample have been reproduced with permission from ref (2) Copyright 2020 American Chemical Society

Table S3. Summary of ex situ XAS. Mo-O refers to the path with bond length $<1.9 \AA$ which is associated with the $\mathrm{MoO}_{3}$ structure, while Mo-(N/O) refers to the path at bond length of $\sim 2.1 \AA$, which is associated with the MoN structure, but could be occupied with either O or N. It should be noted that in the text we refer to this as Mo-N to be concise.

\begin{tabular}{|c|c|c|c|c|c|c|c|c|c|}
\hline Sample & $\begin{array}{c}\text { Pre-edge } \\
\text { peak max } \\
\text { intensity } \\
\text { (A.U.) }\end{array}$ & $\begin{array}{l}\text { White line } \\
\text { max } \\
\text { intensity } \\
\text { (A.U.) }\end{array}$ & $\begin{array}{l}\text { Mo-(O) } \\
\text { coord. }\end{array}$ & $\begin{array}{l}\text { Mo-(O) bond } \\
\text { length }[A]\end{array}$ & $\begin{array}{l}\text { Mo-(N/O) } \\
\text { coord. }\end{array}$ & $\begin{array}{c}\text { Mo-(N/O) } \\
\text { bond length } \\
{[A]}\end{array}$ & $\begin{array}{l}\text { Mo-Mo } \\
\text { coord. }\end{array}$ & $\begin{array}{l}\text { Mo-Mo bond } \\
\text { length }[\mathrm{A}]\end{array}$ & $E_{o}[e V]$ \\
\hline $\begin{array}{c}\text { Surface: } \\
\text { As-prepared }\end{array}$ & 0.0511 & 1.16 & $1.3 \pm 0.3$ & $1.72 \pm 0.01$ & $2.0 \pm 0.4$ & $2.11 \pm 0.02$ & $1.23 \pm 0.27$ & $2.98 \pm 0.02$ & $20021.3 \pm 2.8$ \\
\hline $\begin{array}{c}\text { Surface: } \\
\text { Post } 1 \text { h CA }\end{array}$ & 0.0428 & 1.19 & $1.2 \pm 0.2$ & $1.73 \pm 0.01$ & $4.3 \pm 0.3$ & $2.10 \pm 0.01$ & $2.03 \pm 0.22$ & $2.94 \pm 0.01$ & $20014.6 \pm 1.2$ \\
\hline $\begin{array}{c}\text { Bulk: } \\
\text { As-prepared }\end{array}$ & 0.0345 & 1.13 & - & - & $3.9 \pm 0.2$ & $2.11 \pm 0.01$ & $1.54 \pm 0.23$ & $2.89 \pm 0.01$ & $20014.3 \pm 1.1$ \\
\hline $\begin{array}{c}\text { Bulk: } \\
\text { Post } 1 \mathrm{~h} \mathrm{CA}\end{array}$ & 0.0367 & 1.16 & - & - & $4.0 \pm 0.4$ & $2.10 \pm 0.02$ & $1.47 \pm 0.35$ & $2.89 \pm 0.02$ & $20013.5 \pm 1.8$ \\
\hline
\end{tabular}
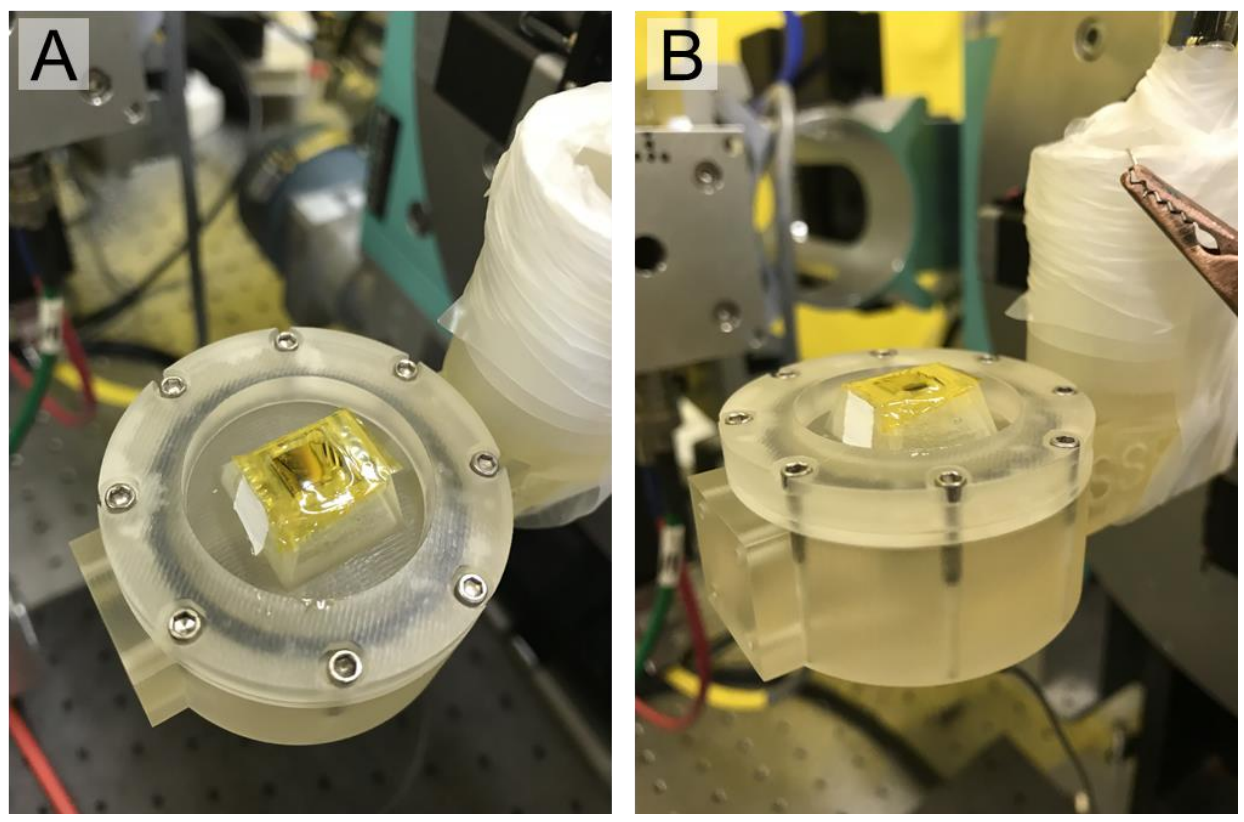

Figure S7. Photos from the GI-cell during beam time highlighting the (A) top and (B) side view of the sample and $\mathrm{x}$-ray window. 

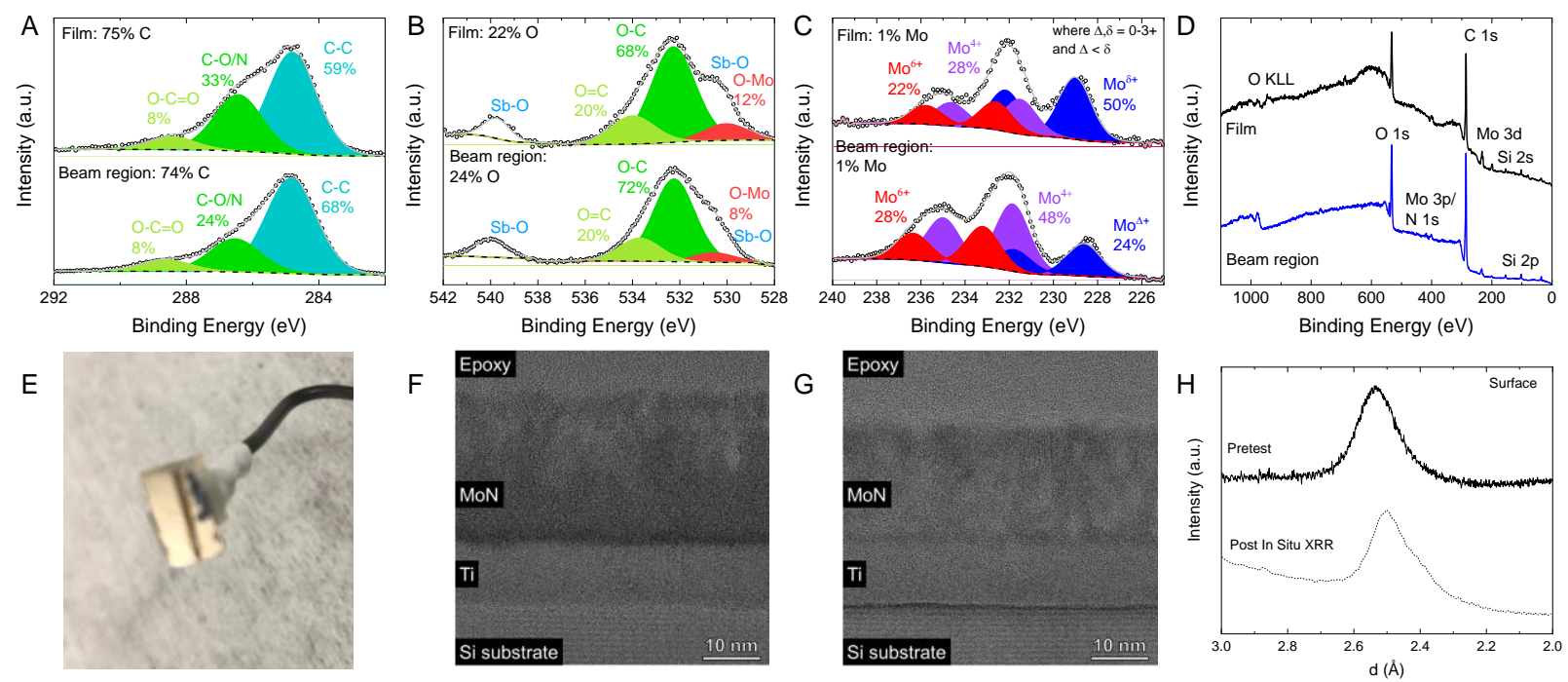

Figure S8. Characterization of the film surface after the in situ XAS measurements. High resolution XPS spectra for the film and the beam exposed regions for (A) C 1s, (B) O 1s, and (C) $\mathrm{Mo} 3 \mathrm{~d}$ and (D) survey spectra. $\mathrm{Sb}$ contamination in the $\mathrm{O} 1 \mathrm{~s}$ region is due to exposure to $\mathrm{Sb}$ during storage between testing and XPS measurements. The Mo 3p/N 1s spectra are not shown due to the low signal. (E) Photograph of film after testing; dark line on the film surface is the beam exposed region. Cross-sectional TEM images of $(\mathbf{F})$ the film and $(\mathbf{G})$ beam damage regions. (H) GI-XRD measurements of the Mo-N film before and after the in situ XRR experiments, showing the main MoN (20) 0 ) peak. The pretest measurement was conducted at an incidence angle of th 0.16 , while the post in situ analysis used th 0.12 . The angles were chosen based on the angle curve to probe the same depth of approximately the top $3-5 \mathrm{~nm}$. 

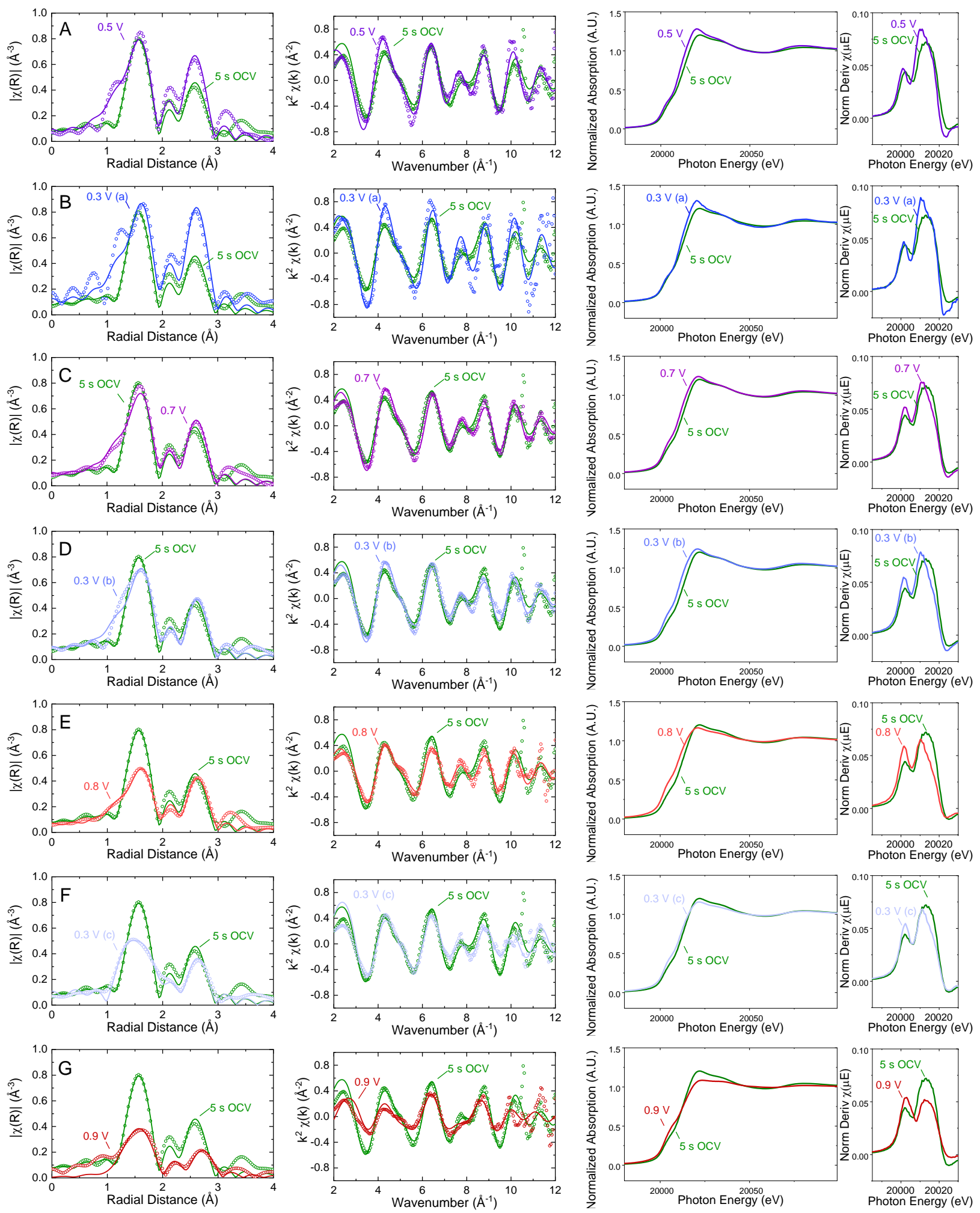

Figure S9. Surface in situ XAS plots. EXAFS fits in R-space and k-space and normalized and derivative XANES of the ex situ $5 \mathrm{~s}$ at OCV film (green) compared with the (A) $0.5 \mathrm{~V}$, (B) $0.3 \mathrm{~V}$ (a), (C) $0.7 \mathrm{~V}$, (D) $0.3 \mathrm{~V}$ (b), (E) $0.8 \mathrm{~V}$, (F) $0.3 \mathrm{~V}$ (c), and (G) $0.9 \mathrm{~V}$ vs RHE in situ data. 
Table S4. Summary of surface EXAFS

\begin{tabular}{|c|c|c|c|c|c|c|c|}
\hline Sample & $\begin{array}{l}\text { Mo-(O) } \\
\text { coord. }\end{array}$ & $\begin{array}{c}\text { Mo-(O) bond } \\
\text { length }[A]\end{array}$ & $\begin{array}{l}\text { Mo-(N/O) } \\
\text { coord. }\end{array}$ & $\begin{array}{l}\text { Mo-(N/O) bond } \\
\text { length }[A]\end{array}$ & $\begin{array}{l}\text { Mo-Mo } \\
\text { coord. }\end{array}$ & $\begin{array}{c}\text { Mo-Mo bond } \\
\text { length }[A]\end{array}$ & $E_{o}[e V]$ \\
\hline $5 s$ at $O C V^{*}$ & $1.1 \pm 0.3$ & $1.73 \pm 0.02$ & $4.5 \pm 0.5$ & $2.09 \pm 0.01$ & $1.7 \pm 0.3$ & $2.90 \pm 0.01$ & $20012.6 \pm 1.4$ \\
\hline $0.5 \mathrm{~V}$ & - & - & $4.1 \pm 0.4$ & $2.11 \pm 0.01$ & $2.6 \pm 0.4$ & $2.91 \pm 0.01$ & $20009.0 \pm 1.4$ \\
\hline $0.3 \mathrm{~V}(\mathrm{a})$ & - & - & $4.1 \pm 0.5$ & $2.12 \pm 0.02$ & $3.3 \pm 0.6$ & $2.91 \pm 0.01$ & $20013.0 \pm 1.9$ \\
\hline $0.7 \mathrm{~V}$ & - & - & $3.5 \pm 0.2$ & $2.11 \pm 0.01$ & $1.9 \pm 0.2$ & $2.91 \pm 0.01$ & $20013.4 \pm 0.9$ \\
\hline $0.3 \vee(b)$ & - & - & $3.5 \pm 0.3$ & $2.12 \pm 0.01$ & $1.7 \pm 0.3$ & $2.92 \pm 0.01$ & $20013.5 \pm 1.4$ \\
\hline $0.8 \mathrm{~V}$ & - & - & $2.4 \pm 0.1$ & $2.12 \pm 0.01$ & $1.7 \pm 0.1$ & $2.92 \pm 0.01$ & $20013.6 \pm 0.8$ \\
\hline $0.3 \mathrm{~V}(\mathrm{c})$ & $\begin{array}{l}1.2 \pm 0.7 \\
2.3 \pm 0.7\end{array}$ & $\begin{array}{l}1.67 \pm 0.02 \\
1.93 \pm 0.03\end{array}$ & $3.6 \pm 1.1$ & $2.14 \pm 0.02$ & $1.4 \pm 0.3$ & $2.91 \pm 0.03$ & $20011.5 \pm 2.4$ \\
\hline $0.9 \mathrm{~V}$ & $0.8 \pm 0.2$ & $1.71 \pm 0.02$ & $2.1 \pm 0.4$ & $2.12 \pm 0.02$ & $0.8 \pm 0.3$ & $2.98 \pm 0.03$ & $20019.1 \pm 2.8$ \\
\hline
\end{tabular}

EXAFS Fitting Notes: The EXAFS data was fit either with MoN paths only, or with a combination of $\mathrm{MoN}$ and $\mathrm{MoO}_{3}$ paths. See Figure S3 for discussion of evaluating fits. Mo-O refers to the path with bond length $<1.9 \AA$ which is associated with the $\mathrm{MoO}_{3}$ structure, while Mo-(N/O) refers to the path at bond length of $\sim 2.1 \AA$, which is associated with the MoN structure, but could be occupied with either $\mathrm{O}$ or $\mathrm{N}$. It should be noted that in the text we refer to this as Mo-N to be concise. Error bars are calculated based on the fit.

The general fitting parameters used: k-range $=3$ to 11.1 , R-range $=1$ to 3 , number of independent points $=10.06, \mathrm{~S}_{0}^{2}=0.8$, and $\sigma^{2}=0.005$. The fits were performed using multiple $\mathrm{k}$-weight corefinement $(\mathrm{k}=1,2,3)$. The $\mathrm{R}$-factor, chi-square, and number of free parameters for each fit are listed in Table S2. In R and k space, the data and fits are plotted with k-weight $=2$.

Note GI-XAS Surface: EXAFS can also provide insight into the local crystal structure, including atomic distances and coordination numbers. In the first EXAFS shell, the Mo-N distance expands slightly $(0.02 \AA)$ relative to the ex situ structure upon application of $0.5 \mathrm{~V}$ vs RHE. The in situ Mo-N distances then do not change substantially after $0.5 \mathrm{~V}(<0.01 \AA)$ as a function of potential or time in electrolyte (Figure S10B). In contrast, the initial in situ Mo-Mo distance is compressed by $\sim 2 \%$ relative to the $\sim 1$ week ex situ and then increases slowly (Figure S10C). At $0.9 \mathrm{~V}$, the film expands further, reaching the same atomic distance as the air exposed film. This Mo-Mo expansion is consistent with the oxidation as seen by $E_{O}$ at these potentials and could suggest that the Mo-Mo lattice expansion is due to $\mathrm{O}$ incorporation. Finally, the coordination numbers $(\mathrm{CN})$ for the first and second shells provide an indication of the $\mathrm{N}$ vacancies/proportion of Mo that is present as crystalline Mo-N in the structure and the size of the crystallites, respectively. Figure S10D shows that the Mo-N coordination starts relatively high and similar to the $\sim 5 \mathrm{~s}$ OCV film; in situ, the coordination number decreases by $\sim 50 \%$ from the first potential to the last, indicating a significant decrease in particle size. It should be noted that the coordination decreases when exposed to higher potentials $(0.5,0.7$, and $0.9 \mathrm{~V}$ vs RHE) and changes negligibly upon returning to $0.3 \mathrm{~V}$ vs RHE (a-c). Finally, Figure S10E shows a slightly different trend, with the initial potentials having larger Mo-Mo CNs than the ex situ samples, but then decreasing steadily after reaching $0.3 \mathrm{~V}$ (a). Once the film is oxidized at $0.9 \mathrm{~V}$ vs RHE, the Mo-Mo CN is very low, suggesting that substantial amorphization is occurring. 


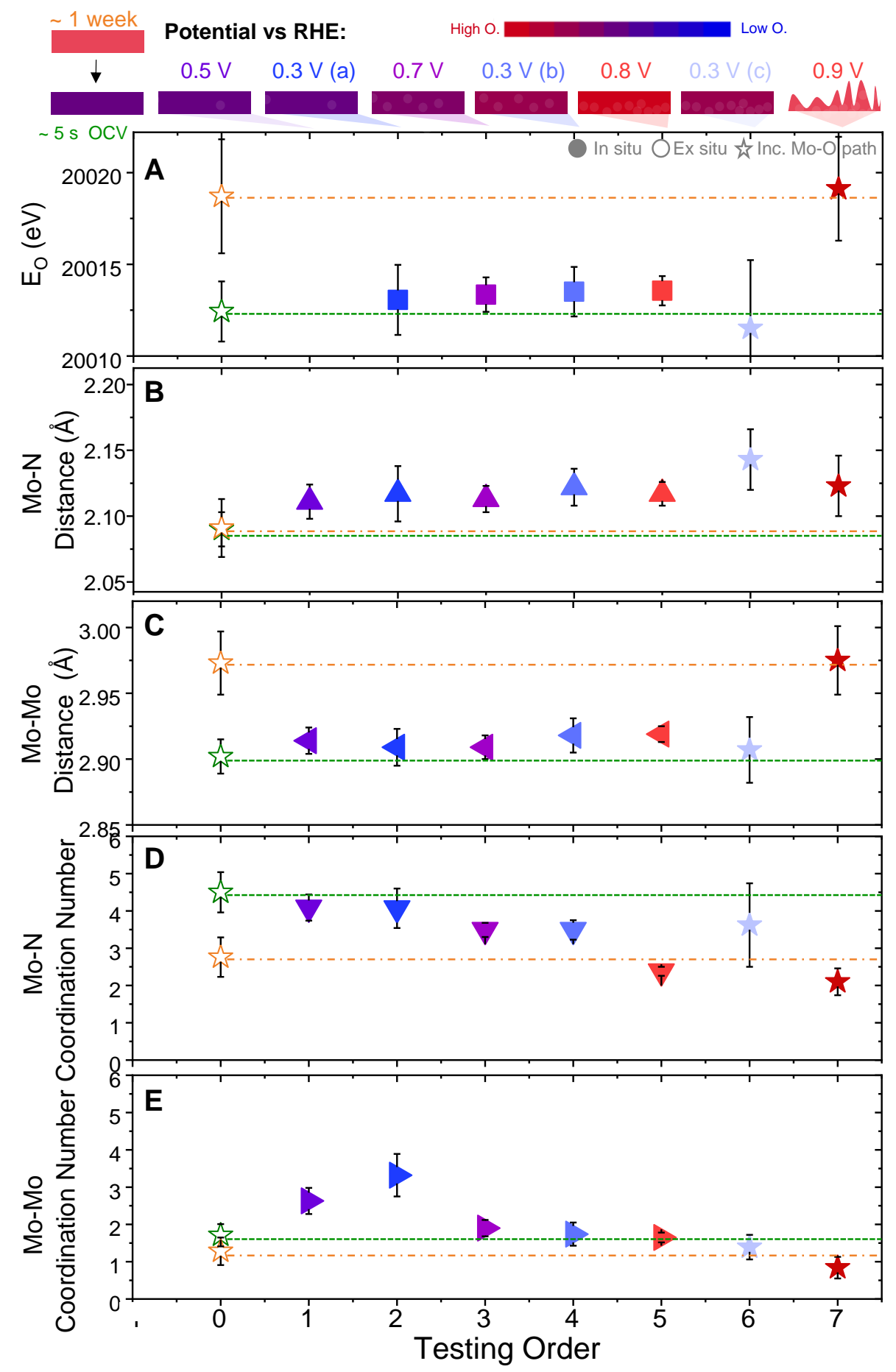

Figure S10. In situ GI-XAS surface EXAFS fit data for Figure 5 of the MoN film with $\mathrm{O}_{2}$-bubbled in $0.1 \mathrm{M} \mathrm{HClO}_{4}$ at a series of different potentials. (A) $\mathrm{EO}_{\mathrm{O}}$, (B) Mo-N and (C) Mo-Mo atomic distances, and (D) Mo-N and (E) Mo-Mo coordination numbers extracted from EXAFS fits at each step noted: $0.5 \mathrm{~V}, 0.3 \mathrm{~V}(\mathrm{a}), 0.7 \mathrm{~V}, 0.3 \mathrm{~V}$ (b), $0.8 \mathrm{~V}, 0.3 \mathrm{~V}$ (c), and $0.9 \mathrm{~V}$ vs RHE, compared to the ex situ $\sim 1$ week in air and $\sim 5 \mathrm{~s}$ at OCV. Error bars are calculated based on the fit. 

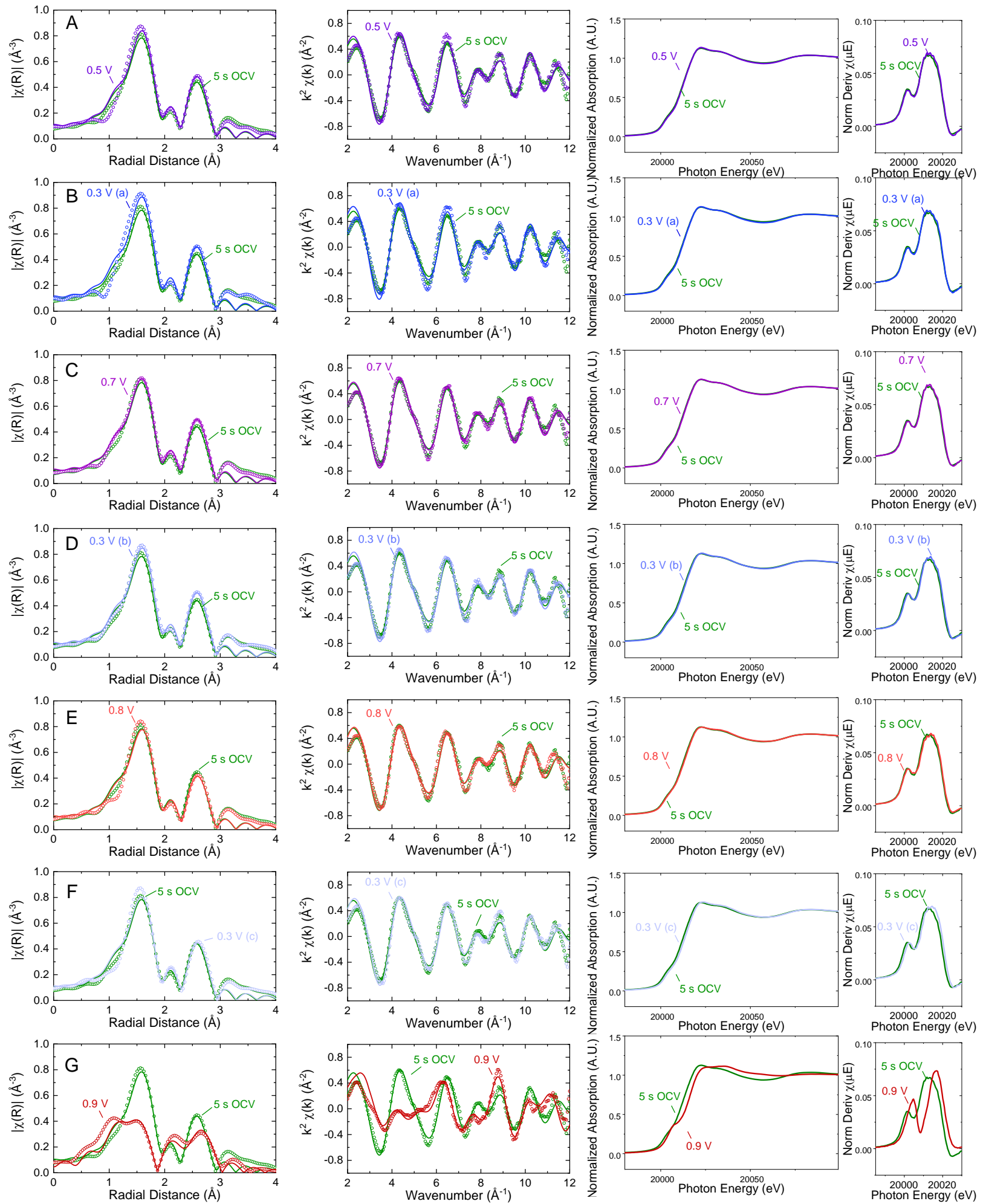

Figure S11. Bulk in situ XAS plots. EXAFS fits in R-space and k-space and normalized and derivative XANES of the ex situ 5s at OCV film (green) compared with the (A) $0.5 \mathrm{~V}$, (B) $0.3 \mathrm{~V}$ (a), (C) $0.7 \mathrm{~V}$, (D) $0.3 \mathrm{~V}$ (b), (E) $0.8 \mathrm{~V},(\mathbf{F}) 0.3 \mathrm{~V}$ (c), and (G) $0.9 \mathrm{~V}$ vs RHE in situ data. 
Table S5. Summary of bulk EXAFS

\begin{tabular}{|c|c|c|c|c|c|c|c|}
\hline \multicolumn{9}{|c|}{ In Situ EXAFS Analysis- BULK } & Mo-(N/O) \\
\hline & $\begin{array}{c}\text { Mo-(O) } \\
\text { coord. }\end{array}$ & $\begin{array}{c}\text { Mo-(O) bond } \\
\text { length }[\mathrm{A}]\end{array}$ & $\begin{array}{c}\text { Mo-(N) bond } \\
\text { coord. } \\
\text { length }[\mathrm{A}]\end{array}$ & $\begin{array}{c}\text { Mo-Mo } \\
\text { coord. }\end{array}$ & $\begin{array}{c}\text { Mo-Mo bond } \\
\text { length }[\mathrm{A}]\end{array}$ & $\mathrm{E}_{\mathrm{o}}[\mathrm{eV}]$ \\
\hline $5 \mathrm{~s}$ at OCV* & & & $3.9 \pm 0.2$ & $2.11 \pm 0.01$ & $1.5 \pm 0.2$ & $2.89 \pm 0.01$ & $20014.4 \pm 1.0$ \\
\hline $0.5 \mathrm{~V}$ & & & $4.2 \pm 0.3$ & $2.11 \pm 0.01$ & $1.7 \pm 0.3$ & $2.89 \pm 0.01$ & $20014.7 \pm 1.5$ \\
\hline $0.3 \mathrm{~V}(\mathrm{a})$ & & & $4.4 \pm 0.4$ & $2.11 \pm 0.01$ & $1.7 \pm 0.4$ & $2.89 \pm 0.02$ & $20014.5 \pm 1.7$ \\
\hline $0.7 \mathrm{~V}$ & & & $4.0 \pm 0.2$ & $2.11 \pm 0.01$ & $1.8 \pm 0.2$ & $2.89 \pm 0.01$ & $20014.8 \pm 0.7$ \\
\hline $0.3 \mathrm{~V}(\mathrm{~b})$ & & & $4.2 \pm 0.2$ & $2.12 \pm 0.01$ & $1.8 \pm 0.2$ & $2.89 \pm 0.01$ & $20015.4 \pm 0.9$ \\
\hline $0.8 \mathrm{~V}$ & & & $3.9 \pm 0.3$ & $2.11 \pm 0.01$ & $1.4 \pm 0.3$ & $2.89 \pm 0.02$ & $20015.3 \pm 1.5$ \\
\hline $0.3 \mathrm{~V}(\mathrm{c})$ & & & $4.0 \pm 0.3$ & $2.10 \pm 0.01$ & $1.6 \pm 0.3$ & $2.89 \pm 0.01$ & $20015.0 \pm 1.5$ \\
\hline $0.9 \mathrm{~V}$ & $2.6 \pm 0.5$ & $1.73 \pm 0.01$ & $1.6 \pm 0.8$ & $2.27 \pm 0.05$ & $1.7 \pm 0.3$ & $2.92 \pm 0.02$ & $200016.0 \pm 3.3$ \\
\hline
\end{tabular}

Note GI-XAS Bulk: Mo-O refers to the path with bond length $<1.9 \AA$ which is associated with the $\mathrm{MoO}_{3}$ structure, while Mo-(N/O) refers to the path at bond length of $\sim 2.1 \AA$, which is associated with the MoN structure, but could be occupied with either $\mathrm{O}$ or N. It should be noted that in the text we refer to this as Mo-N to be concise. Error bars are calculated based on the fit.

There are distinct differences between the surface and the bulk of the film, in particular the bulk changes only minimally with applied potential. Generally, the bulk of the film is less expanded than the surface (by $0.002 \AA$ and $0.03 \AA$ on average for Mo-N and Mo-Mo, respectively), and this trend holds for ex situ and in situ conditions at all potentials. The Mo-N CN is also generally higher in the bulk than the surface $(\sim 15 \%)$, while the Mo-Mo CN is lower in the bulk $(\sim 25 \%)$. The lower Mo-N CN at the surface may be due to loss of $\mathrm{N}$ or distortion of the structure with the introduction of $\mathrm{O}$. The indicators of distortion and oxidation, the pre-edge feature and $\mathrm{E}_{\mathrm{O}}$, show only small changes from the ex situ in the $0.3-0.8 \mathrm{~V}$ vs RHE potential range. It should be noted, however, that the pre-edge intensity is much lower than at the surface, while the Eo values are higher in the bulk. These should not be directly compared due to differential self-absorption effects between the surface and bulk.

As shown in Table S5 and Figures S11-12, there are negligible changes to the bulk of the film from ex situ to all in situ potentials before $0.9 \mathrm{~V}$ vs RHE. The Mo-N and Mo-Mo coordination numbers and bond lengths do not change, and there are only minor variations in the pre-edge intensity and $E_{o}$. Significant changes occur at $0.9 \mathrm{~V}$ vs RHE (Figure 6B), including an increase in the pre-edge intensity, decrease in coordination for the Mo-N and Mo-Mo paths, and the addition of $\mathrm{MoO}_{3} \mathrm{Mo}-\mathrm{O}$ paths to the fit, overall indicating increases in $\mathrm{O}$ incorporation and amorphization. 


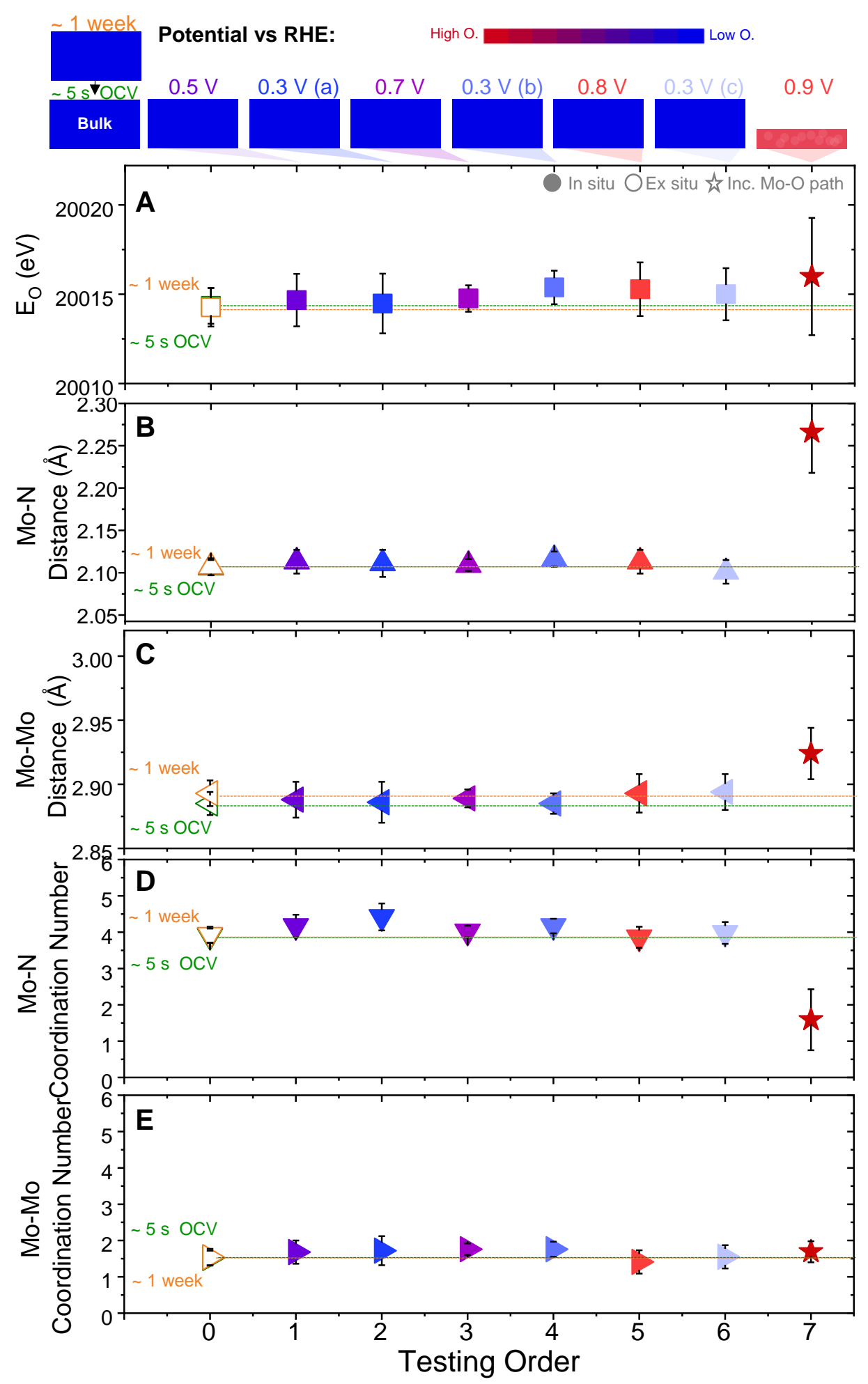

Figure S12. In situ GI-XAS bulk EXAFS fit data for Figure 5 of the MoN film with $\mathrm{O}_{2}$-bubbled in $0.1 \mathrm{M} \mathrm{HClO}_{4}$ at a series of different potentials. (A) $\mathrm{E}_{\mathrm{O}}$, (B) Mo-N and (C) Mo-Mo atomic distances, and (D) Mo-N and (E) Mo-Mo coordination numbers extracted from EXAFS fits at each step noted: $0.5 \mathrm{~V}, 0.3 \mathrm{~V}$ (a), $0.7 \mathrm{~V}, 0.3 \mathrm{~V}$ (b), $0.8 \mathrm{~V}, 0.3 \mathrm{~V}$ (c), and $0.9 \mathrm{~V}$ vs RHE, compared to the ex situ 1 week in air and $5 \mathrm{~s}$ at OCV. Error bars are calculated based on the fit. 


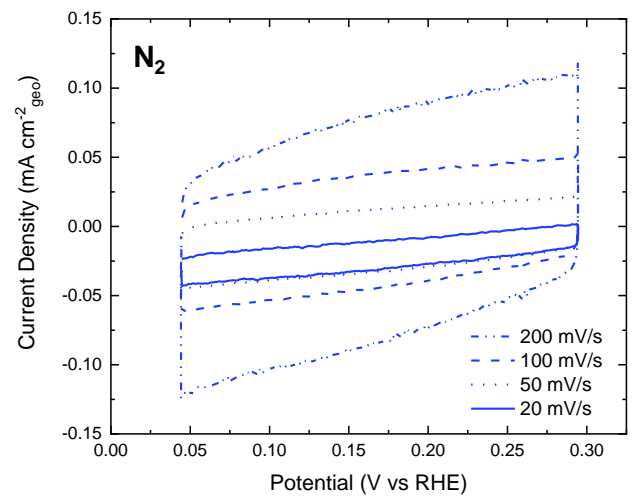

Figure S13. Cyclic voltammograms in $\mathrm{N}_{2}$-saturated electrolyte in the $0.05-0.3 \mathrm{~V}$ vs RHE potential window at varied scan rates, which are used to evaluate the electrochemical double layer capacitance (EDLC).
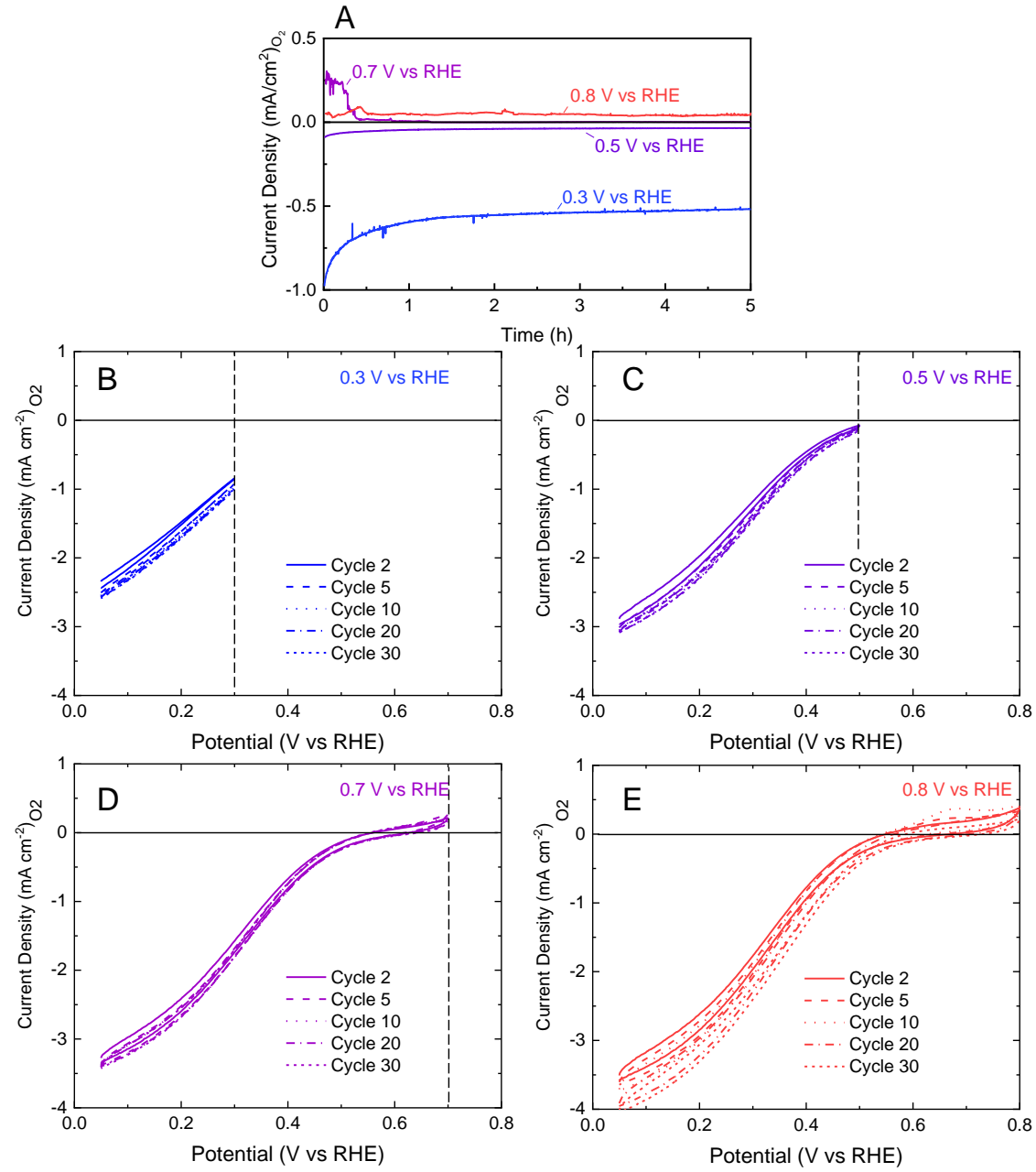

Figure S14. ORR potential stability measured using (A) $5 \mathrm{~h}$ chronoamperometry (CA) measurements at 0.3, 0.5, 0.7, $0.8 \mathrm{~V}$ vs RHE for the ICP-OES measurements in Figure 4C and 30 cycles from $0.05 \mathrm{~V}$ to (B) $0.3 \mathrm{~V}$, (C) $0.5 \mathrm{~V}$, (D) $0.7 \mathrm{~V}$, (E) $0.8 \mathrm{~V}$ vs RHE. All measurements were 
done in $\mathrm{O}_{2}$ sparged $0.1 \mathrm{M} \mathrm{HClO}_{4}$ rotating at $1600 \mathrm{rpm}$. CA measurements were done with different MoN films for each potential on Si substrates attached to a GC disc. Cycling stability was done sequentially starting at the lowest potential range with the MoN deposited directly onto the GC substrate.
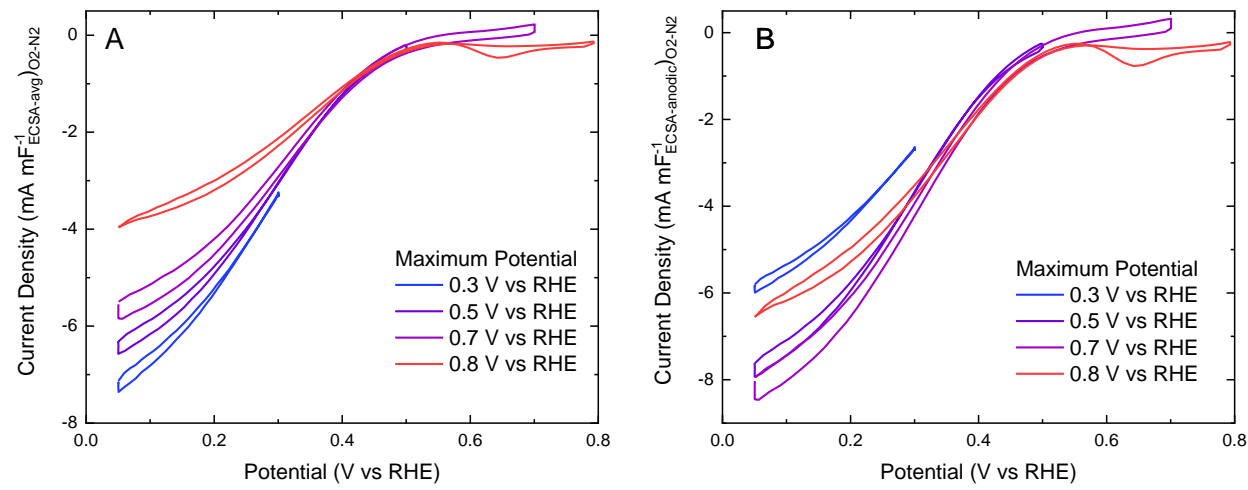

Figure S15. ORR CVs in the 4 potential windows normalized by the (A) average EDLC and (B) anodic EDLC.
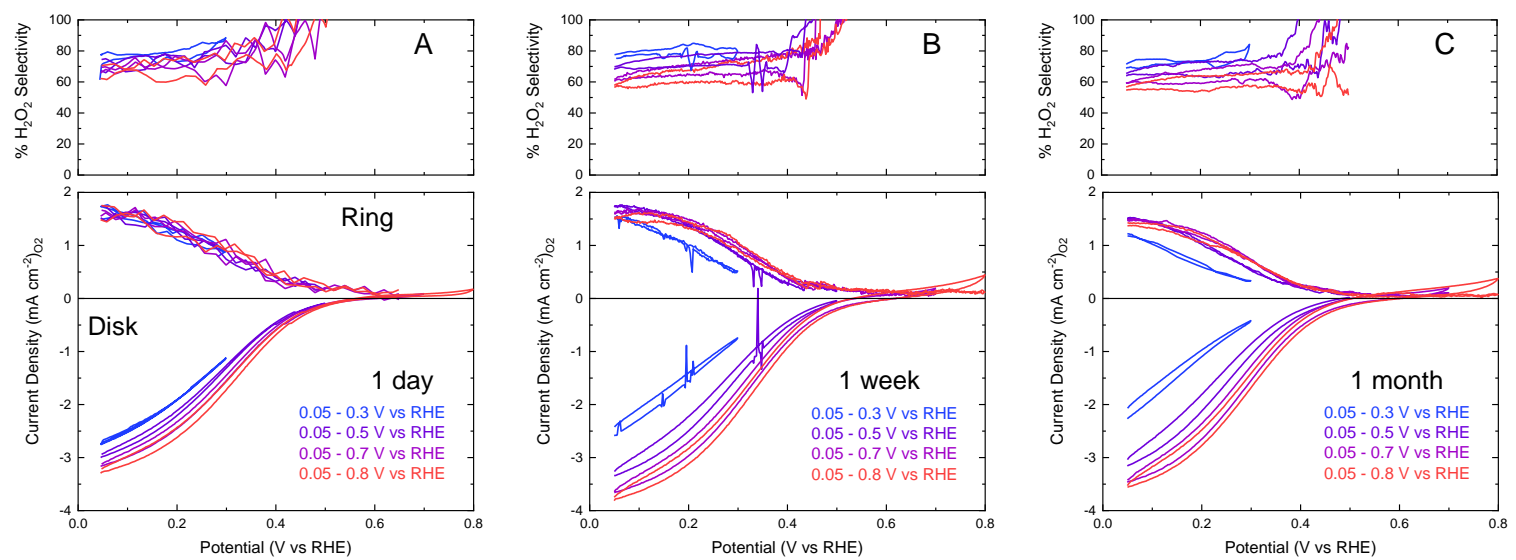

Figure S16. RRDE ORR CVs of MoN in the 4 potential windows after different lengths of air exposure: (A) 1 day, (B) 1 week, and (C) 1 month. Initial activity decreases with time in air, but the activity is recovered after cycling to higher potentials. (Top) $\% \mathrm{H}_{2} \mathrm{O}_{2}$ selectivity and (bottom) ring (corrected for $\sim 20 \%$ collection efficiency) and disk current. Average selectivity for the $0.05-0.3 \mathrm{~V}$ vs RHE cycle is $80 \%$, while the average for the $0.05-0.8 \mathrm{~V}$ vs RHE cycle is $65 \%$ (in this same 0.05-0.3 V vs RHE window). 

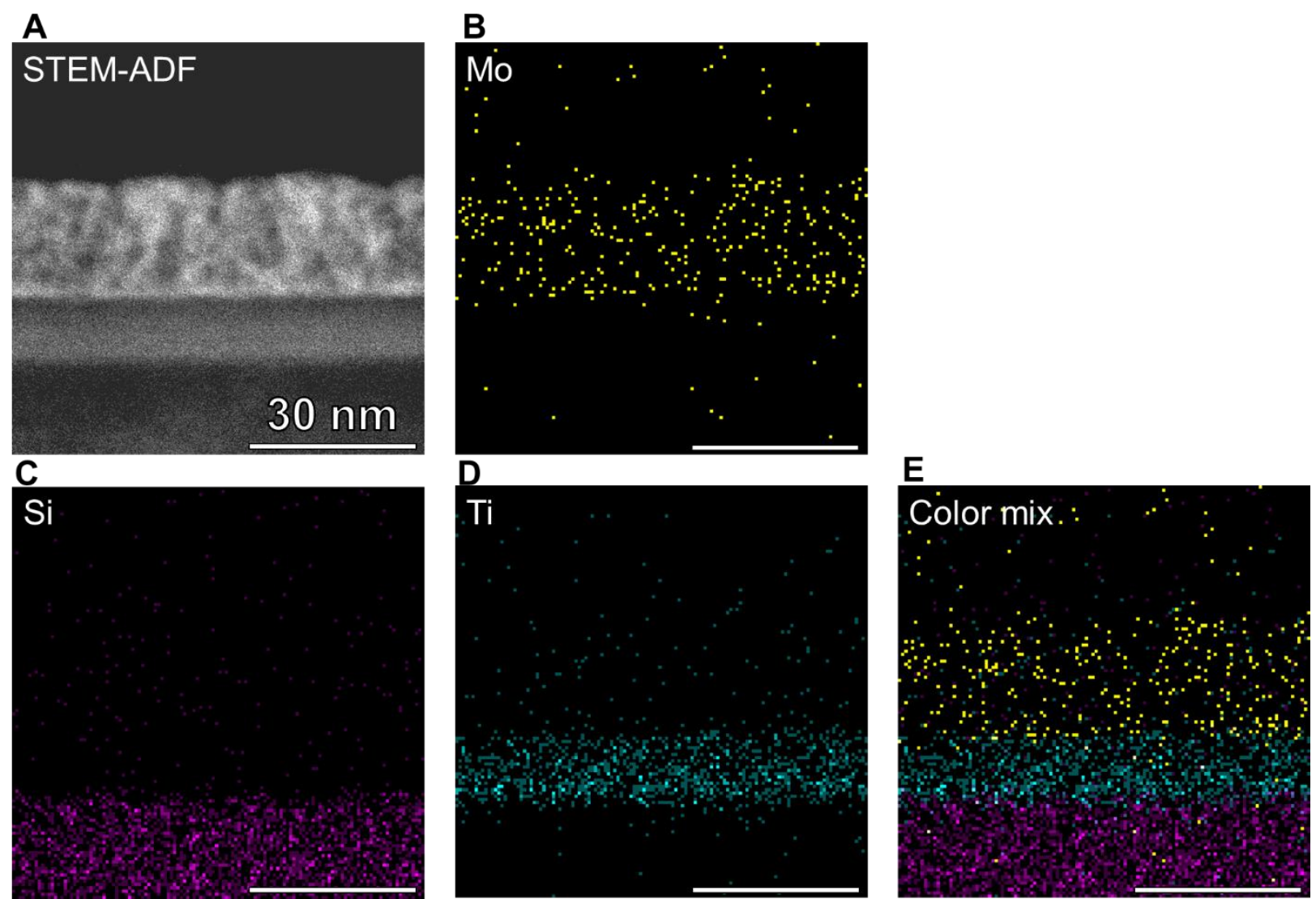

Figure S17. Cross-section STEM-EDS mapping of MoN thin film post X-ray in situ analysis. (A) STEM-annular dark field (ADF) image of elemental mapped area, (B-D) elemental mapping for $\mathrm{Mo}, \mathrm{Si}$, and $\mathrm{Ti}$, respectively, and (E) color mix of the three maps in (B-D). X-ray signals for the lighter elements $(\mathrm{O}, \mathrm{N})$ were not sufficient to generate maps.

Table S6: DFT-computed O substitution energies for bulk cubic and hexagonal MoN structures

\begin{tabular}{|c|c|c|c|}
\hline $\begin{array}{c}\text { Crystal } \\
\text { Structure }\end{array}$ & $\begin{array}{c}\text { O Concentration } \\
\mathbf{( \% )}\end{array}$ & $\begin{array}{c}\text { O Substitution } \\
\text { Formation } \\
\text { Energy at 0 V } \\
\text { vs. RHE (eV) }\end{array}$ & $\begin{array}{c}\text { Voltage at 0 eV O } \\
\text { Substitution } \\
\text { Formation Energy (V } \\
\text { vs. RHE) }\end{array}$ \\
\hline Cubic & 0 & 1.8 & 0.9 \\
\hline Cubic & 6.25 & 1.2 & 0.6 \\
\hline Hexagonal & 0 & 1.2 & 0.6 \\
\hline Hexagonal & 6.25 & 1.1 & 0.5 \\
\hline
\end{tabular}




\section{References}

(1) Calvin, S. XAFS for Everyone; CRC Press: Boca Raton, FL, 2013.pp1 - 449.

(2) Kreider, M. E.; Stevens, M. B.; Liu, Y.; Patel, A. M.; Statt, M. J.; Gibbons, B. M.; Gallo, A.; Ben-Naim, M.; Mehta, A.; Davis, R. C.; Ievlev, A. V.; Nørskov, J. K.; Sinclair, R.; King, L. A.; Jaramillo, T. F. Nitride or Oxynitride ? Elucidating the Composition - Activity Relationships in Molybdenum Nitride Electrocatalysts for the Oxygen Reduction Reaction. Chem. Mater. 2020, 37, 2946-2960. 